\title{
Cytotoxicity of Insects (T. Molitor, G. Bimaculatis, S. Gregaria and A. Domesticus) in A Simulated Gastrointestinal Digestion/Human Intestinal Cell Model
}

\section{Darja Dobermann}

Chalmers University of Technology

Nathalie Scheers ( $\nabla$ Nathalie.scheers@chalmers.se )

Chalmers University of Technology

\section{Research Article}

Keywords: Insects, Caco-2, Catalase, Viability, Cell survival, FOSB

Posted Date: January 7th, 2021

DOI: https://doi.org/10.21203/rs.3.rs-138966/v1

License: (c) (1) This work is licensed under a Creative Commons Attribution 4.0 International License. Read Full License 


\section{Abstract}

Insects as an alternative nutritional source for protein and other nutrients has gained increasing attention in the last decade. On the other hand, insects produce several compounds toxic to human cells associated with e.g. antitumoral activity and as such has been proposed as tentative anti-cancer agents. In this work, we used a combined simulated gastrointestinal digestion and human absorptive cell model, Caco-2, common in nutritional studies but also in cancer research, to investigate cytotoxicity of common insect species in a simulated oral intake setting. Caco-2 cells were exposed to various concentrations of digested insects (Gryllus bimaculatus, Schistocerca gregaria, Tenebrio molitor, Acheta domesticus) which showed a significant decrease in survival and viability in response to the digests. T. molitoraffected the viability of Caco-2 cells the most, compared to the other species. Notable effects on protein expression of several calcium homeostasis and cell response related proteins, FOSB, BANK1 and EGFL7, a metabolic homeostasis oxidative stress response related protein, $\mathrm{FOXO1}$, and an apoptosis related protein, $\mathrm{HO}$ $1 /$ HMOX/HSP32 was identified. We conclude that these insect species were cytotoxic to the intestinal cells in a simulated oral intake setting.

\section{Introduction}

Human nutrition and insects. Global micronutrient deficiencies are among the most prevalent deficiencies within malnutrition challenges and seen disproportionately in women of reproductive age (WRA), pregnant women, and children in developing countries [1]. Suboptimal levels in any of the primary micronutrients: iron, zinc, vitamin A, folate, vitamin D, and iodine, are associated with an increased risk of the following consequences: maternal mortality, maternal morbidity, low birth weights, and subpar health and cognitive development of children [2]. Globally, upwards of $40 \%$ of pregnant women and more than 290 million children under the age of 5 are anaemic [3-6]. Insects have been suggested as a novel solution to anaemia. Edible insects have been documented to contain high iron levels and have thus surfaced a potential alternative food choice $[7,8]$. Overall insects are good sources of energy, protein, fat, minerals, and vitamins within the human diet [9]. The energy provided by insects has been established to be on par with other fresh meat sources per fresh weight [9]. Mean estimates show energy levels to be around 400-500 kcal per $100 \mathrm{~g}$ of dry insect matter, making it a competitive food option when presented next to other protein sources. From a micronutrient perspective, levels of the key micronutrients: iron, zinc, vitamin $A$, folate, vitamin $D$, and iodine vary depending on insect species, however, folate, vitamin $D$, iodine are generally not present in notable amount. Iron, specifically, has been shown to range from 18 to $1562 \mathrm{mg} / 100 \mathrm{~g}$ dry insect matter across species, with the low end of the spectrum encompassed by ants, the mid-level being termites and the highest levels found in crickets[10]. For this reason, suggestions have been made to use insects documented to be high in iron as an alternative food source to help reduce the prevalence of iron deficiency anaemia.

Insects as potential cancer therapy. Insects produce a large number of species-dependent bioactive substances needed for survival, and for this, insects have attracted interest from the pharmacology research field and several investigations have shown harmful effects to human cancer cells of different 
origin e.g. anti-proliferative compounds extracted from the Texas grasshopper were shown to inhibit growth of human leukemic leucocytes [11] and insect (Hydrillodes repugnalis) tea was shown to inhibit viability of human hepatoma (HepG2) cells [12]. Yet another study, looking at both HepG2 and Caco-2 (undifferentiated cells, 4 days post-seeding) observed decreased viability after incubation with T.molitor (mealworm larvae)[13]. Also, in vivo studies in mice have shown that insect alleferons have antitumoral activity [14]. These are only a few examples from a large body of studies on insects and insect-derived compounds for the potential use in cancer therapy.

The present study. The aim of the present study was to examine toxicity of insects to human intestinal cells in a simulated gastrointestinal setting using a standard model for nutrient absorption. As such, the insects went through a simulated gastrointestinal digestion procedure before they were further digested and absorbed by human intestinal Caco-2 cells. The digests were incubated with undifferentiated cells (colonic characteristics) as most cytotoxicity studies are done in undifferentiated cells, but also with fully differentiated Caco-2 epithelia (duodenal characteristics) as appropriate for in vitro studies on intestinal uptake/absorption of nutrients to also cover the effects of gastrointestinal processing of the nutrient before it meets the absorptive cells. We investigated four popular insect species Gryllus bimaculatus (black cricket), Tenebrio molitor (yellow mealworm), Schistocerca gregaria (desert locust), and Acheta domesticus (house cricket). We also used two species from an alternative source (in the Netherlands) to verify that the observed cytotoxicity was not connected to the primary source (in the UK). We undertook viability and cell survival experiments at different concentrations of the insect digests complemented with catalase activity testing and protein arrays to gain mechanistic insight.

\section{Materials And Methods}

Materials. Unless otherwise stated, all reagents and chemicals were purchased from Sigma-Aldrich. aamylase (A3176, $\geq 10$ units/mg solid), porcine pepsin (P-7125, $\geq 400$ units/mg protein), porcine pancreatin (P-1750) and porcine bile extract (B-8631) were stored as directed until use. A Milli-Q plus system (Merck Millipore, Darmstadt, Germany) was used to purify water to a minimum resistance of 18.2 $\mathrm{M} \Omega \mathrm{cm}$. All other chemicals, such as solvents used, were of analytical grade. Solutions of enzymes were prepared fresh before each use. The first round of insects was sourced from a farm in the United Kingdom. Insects were received fresh, immediately frozen to kill, then oven dried at $80^{\circ} \mathrm{C}$ for 36 hours, prior to grinding in a coffee grinder. All were stored at $-20^{\circ} \mathrm{C}$ when not in use. The second round of insects were purchased from the online platform Bug Bazaar.

Simulated gastrointestinal digestion. $1 \mathrm{~g}$ of each insect sample was weighed out for digestion. To each sample, $5 \mathrm{ml}$ of a-amylase solution ( 75 units/ $\mathrm{ml}$ in MQ) was added and sample agitated on a rotating plate (200 RPM) for two minutes. Following this $5 \mathrm{ml}$ of MQ water was added and pH adjusted to 2 using $\mathrm{HCl}(6 \mathrm{M})$. During peptic digestion, $0.3 \mathrm{ml}$ of pepsin solution $(0.15 \mathrm{~g} / \mathrm{ml})$ was added and incubated at $37^{\circ} \mathrm{C}$ for 60 mins on rotating plate (70 RPM), followed by $\mathrm{pH}$ to 7 with $\mathrm{NaOH}(5 \mathrm{M})$ to stop peptic digestion. Afterward, $1.7 \mathrm{ml}$ of pancreatin-bile solution $(24 \mathrm{mg} / \mathrm{ml}$ bile extract and $4 \mathrm{mg} / \mathrm{ml}$ pancreatin) was added to start pancreatin-bile digestion and samples incubated at $37^{\circ} \mathrm{C}$ for 60 mins on rotating plate (70 RPM). 
Following digestion, sample volumes were brought up to $15 \mathrm{ml}$ using $\mathrm{MQ}$ water and stored at $-20^{\circ} \mathrm{C}$ until use. Samples were not heat inactivated to avoid degradation of the insect material which would not be true to physiological reality i.e. digestion does not involve a point at which material reaches above body temperature. Trials using only non-heat-inactivated in vitro digestion fluids at varying concentrations showed these had no significant impact on cell survival or viability over 24 hours at levels utilised in this trial (supplemental data).

Caco-2 cell culture. We were using the human intestinal Caco-2 cell line as the cells form an epithelial layer which displays several morphological and functional characteristics of mature enterocyte when grown in post-confluent cultures [30,31]. Further, a strong correlation has been found between published human absorption data and uptake by Caco-2 cells, establishing this method as useful in assessing iron bioavailability [32]. Caco-2 cells (ATCC; HTB-37) were obtained at passage 21 and 29 and used in experiments until passage 68. Cells were grown in Eagle's Minimum Essential Medium (EMEM, BioWhittaker, BE12-125F) with 10\% fetal bovine serum (FBS, Gibco, 10500-064), 1\% L-Glutamine (200mM, BioWhittaker, $17-605 \mathrm{E}$ ), and $0.18 \%$ Normocin (InvivoGen, ant-nr-2) at $37^{\circ} \mathrm{C}$ with $5 \% \mathrm{CO}_{2}$ and $95 \%$ humidified air with medium changed every two days. The cells were passaged at $80 \%$ confluence using trypsin-EDTA (0.05\%, Gibco, 25300-054).

Cell survival measures. Cells were plated in 24 -well plates (90,000 cells/well, Corning CellBIND) and cultured for 24 hours or 14 days, dependent on if the experiment was with differentiated or nondifferentiated cells. Cell medium was changed 24 hours prior to the start of the trial. The cells were incubated with digest dilutions for 24 hours, following which digests and medium were aspirated and cells washed twice with DPBS. Cells were lysed in $100 \mu \mathrm{l}$ cold RIPA buffer with added PPI, collected and stored at $-80^{\circ} \mathrm{C}$ until analysis. Digest dilutions with which cells were treated, were made by mixing digests with cell medium already present on the cells. In order to approximate actual insect concentrations represented by these dilutions $(\mathrm{mg} / \mathrm{ml})$ on the cells, it was assumed that $100 \%$ of the insect was digested in the $15 \mathrm{ml}$ of digestion fluid. Given this, it was assumed that base digest prior to dilution contained $66.67 \mathrm{mg}$ of insect per $\mathrm{ml}$ of digestion fluid. It is acknowledged that $100 \%$ digestion of the insect samples is an overestimate, as evidenced by visible precipitate in the digests. Total cell density (surface attached) as a proxy for cell survival after treatment with the various insect digests and controls were estimated by measuring the total protein content per well by using the Pierce BCA Protein Assay Kit [33].

Cell viability estimated by the MTT assay. The cells were cultured, maintained, and seeded as stated above in 2.3. and 2.5; cells were seeded in 96-well plates (10,000 cells/well, Corning CellBIND) and cultured for 24 hours. Cell viability was measured based on metabolic reduction of 3-(4,5-dimethylthiazol2-yl)-2,5-diphenyltetrazolium bromide as measured by MTT Cell Growth Kit (MTT, Merck Millipore, CT02). Dimethyl sulfoxide (DMSO) was used to dissolve MTT crystals in place of acidified isopropanol, as it was ineffective.

Expression of stress-related protein markers. The protein levels of apoptosis-related proteins were identified using the Proteome Profiler ${ }^{\text {TM }}$ antibody arrays (Human Apoptosis Array Kit; R\&D Systems, MN, 
USA), which estimates the protein levels of 35 different apoptosis-related human proteins. Pooled samples of cell lysates were loaded on the arrays at $15 \mu \mathrm{g}$ protein/membrane. Membranes with controls, digest controls, and insect digests were processed and developed simultaneously in the same run for each trial. The chemiluminescent signal was developed using a Chemidoc XRS+ (Bio-Rad Laboratories Inc., Hercules, USA). Samples from cells exposed to tolerable and cytotoxic levels of T. molitor and $G$. bimaculatus were additionally sent to OLink Proteomics (Uppsala, Sweden) for analysis with their organdamage panel which analyses 92 protein biomarkers relevant to processes involved in biological response to organ damage.

Verification trials. Verification trials were done to account for potential impact of processing or source of insects utilised. The first verification utilised insect samples heated to $105^{\circ} \mathrm{C}$ for 60 minutes in nonconfluent cells. The second verification examined freeze dried insects, T. molitor and Locusta migratoria, which were explicitly marketed as human food from a farm in the Netherlands in non-confluent cells.

Based on continually updating research these samples were run through a slightly modified simulated gastrointestinal digestion as follows. $1 \mathrm{~g}$ of each insect was weighed out. To each sample $4 \mathrm{ml}$ of salt solution $\left(140 \mathrm{mM} \mathrm{NaCl}\right.$ and $5 \mathrm{mM} \mathrm{KCl}$ ) pre-heated to $37^{\circ} \mathrm{C}$ was added, following which the $\mathrm{pH}$ was adjusted to 7 using $1 \mathrm{M} \mathrm{NaHCO}_{3}$. Sample volume adjusted to $6.5 \mathrm{ml}$ and $500 \mu \mathrm{l}$ of the amylase stock solution (1050 U/ml; Sigma-Aldrich A3176-1MU, $10 \mathrm{U} / \mathrm{mg}$ ) was added to each sample and then incubated at $37^{\circ} \mathrm{C}$ with shaking (165 rpm) for 4 mins. The pH was immediately lowered to 2 using $1 \mathrm{M} \mathrm{HCl}$, and volume of each sample adjusted to $9.5 \mathrm{ml}$ with salt solution. Then $500 \mu \mathrm{l}$ of the pepsin stock solution (40000 U/ml; Sigma-Aldrich P7012-5G, $2529 \mathrm{U} / \mathrm{mg}$ ) was added to each sample and they were incubated at $37^{\circ} \mathrm{C}$ with shaking $(165 \mathrm{rpm})$ for 60 mins. Subsequently the $\mathrm{pH}$ was raised to 5.5 using $1 \mathrm{M} \mathrm{NaHCO}_{3}$ and $2 \mathrm{ml}$ of bile solution (10.635 mg/ml; Sigma-Aldrich B8631-100G, $1.68 \mathrm{U} / \mathrm{mg}$ ) and $0.5 \mathrm{ml}$ of pancreatin solution (7 mg/ml; Sigma-Aldrich $\mathrm{P} 7545,2.6 \mathrm{U} / \mathrm{mg}$ ) were added. The $\mathrm{pH}$ was adjusted to 7 using $1 \mathrm{M} \mathrm{NaHCO}_{3}$, total sample volume adjusted to $15 \mathrm{ml}$ using salt solution and incubated at $37^{\circ} \mathrm{C}$ with shaking (165 rpm) for 60 mins. Digests were stored at $-20^{\circ} \mathrm{C}$ until use. Cells were treated with concentrations previously identified as tolerable or cytotoxic and dilution was done in blank digestion fluids to ensure all cells were equally exposed to digestion enzymes.

Statistical analysis. Data was analysed with Microsoft Office Excel 2016, IBM SPSS Statistics 23 and BioRad Image Lab 6.0.1. Data are shown as means with standard deviation or standard error in which $n=$ number of separate trials, within trials the repeats were between 2-4. Comparison of means was done with Student's $t$-test, equal variances not assumed, two-tailed and significant differences were considered at $p<0.05$.

\section{Results}

Cell survival decreased at increasing concentrations of insects. Cell survival, based on total protein from live cells, was significantly reduced by all insect digests. The dilution point at which cell survival was significantly impacted varied between species and cells treated with $A$. domesticus digests showed 
significantly reduced survival at all concentrations as presented in Figure 1, while cells treated with $G$. bimaculatus and $S$. gregaria digests all had significantly reduced survival rates only at dilutions at and below $0.167 \mathrm{mg} / \mathrm{ml}$. The cells were most resilient to $T$. molitor digests with significant reductions only seen at dilutions levels at and below $0.667 \mathrm{mg} / \mathrm{ml}$.

Decreasing cell viability with increasing concentration of insect digests. Cell viability tests demonstrated that all insect digests significantly reduced cell viability. Average cell viability as measured by the MTT assay, is presented as percentage of control (untreated cells in medium) in Figure 2. Cells treated with $T$. molitor digests showed significantly reduced viability at and below dilutions of $0.667 \mathrm{mg} / \mathrm{ml}$, consistent with the cell survival data in Figure 1. However, the decrease in cell survival of the other three species was evident at slightly lower concentrations of insect digests than the measurable effect on cellular viability. A. domesticus digests only significantly reduce cell viability at and below dilutions of $1.333 \mathrm{mg} / \mathrm{ml}$, while G. bimaculatus and S. gregaria digests only have a significant reduction at and below dilutions of 3.333 $\mathrm{mg} / \mathrm{ml}$.

Stress-related protein markers. Changes in protein expression of one apoptosis related protein with notable presence were identified. HO-1/HMOX-1/HSP32 protein levels consistently showed marked change when analysed with Proteome ProfilerÔ arrays (Human apoptosis array kit, R\&D systems). Array results are plotted in graphs to illustrate this in Figure $\mathbf{3 a}$ and $\mathbf{3 b}$, but due to limited sample availability $(n=1$, pooled triplicate), the array results could not be used for statistical analysis. The data suggested that there were no marked changes in the expression of common apoptosis-related proteins such as procaspase-3, cleaved caspase-3, bad, and bax (data not shown). HO-1/HMOX-1/HSP32 or heme oxygenase 1 , also known as heat shock protein 32 , is a stress-related cytoprotective molecule vital in the protection against oxidative injury. Notable changes in several proteins related to cellular calcium and metabolic homeostasis were identified in a protein panel analysis ( $n=3$; Olink proteomics, Uppsala, Sweden), Figure 3c and 3d. Cells displayed the largest change in FOSB expression for both insect species and also followed the same trends of an initial increase in TNNI3, followed by a decline. FOSB and TNNI3 are responsible for cellular responses to calcium ions and calcium ion homeostasis, respectively. Similarly, EGFL7 controls calcium binding and BANK1 is involved in calcium mobilisation from intracellular storage. While FOXO1 regulates metabolic homeostasis in response to oxidative stress; it is the main regulator of redox balance [15].

Catalase activity in Caco-2 cells was increased. Catalase activity was measured as a secondary marker for oxidative stress response in the cells $[16,17]$. The catalase activity was analysed in cells exposed to insect samples at the dilution point, $1: 20(3.335 \mathrm{mg} / \mathrm{ml}$ at which cell viability or survival was significantly reduced across all tested insect species. The catalase activity in cells exposed to insect digests was elevated, with some variability between species. G. bimaculatus and $S$. gregaria caused the highest increase $(116 \%$ increase $(p=.002)$ and $177 \%$ respectively, $(p=.000))$ and T. molitor and $A$. domesticus a slightly smaller increase (43\% ( $p=.001)$ and $63 \%(p=.000)$ respectively) compared to digestion fluid control, Figure 4. This distinct increase in catalase activity further suggests that the cells were responding to an oxidative stressor [18-20]. 
Verification trials in another insect source - cell survival. Verification trials utilising insect samples from an alternative source (the Netherlands) confirmed previous findings that cell survival, based on total protein from live cells, was significantly reduced by all insect digests at the $3.333 \mathrm{mg} / \mathrm{ml}$ dilution level as presented in Figure 5. For T. molitor significant reductions were again seen at dilutions levels at and below $0.667 \mathrm{mg} / \mathrm{ml}$. Trials utilising insects which were heated to $105^{\circ} \mathrm{C}$ for 60 minutes, Figure 6 , prior to digestion and treating the cells confirmed similar trends, although more variation in response was observed suggesting processing temperature may play a role in toxicity of the insects to cells.

\section{Discussion}

Oxidative stress as a possible cause for cell cytotoxicity. While these analyses do not elucidate the exact mechanism by which the insect digests are killing the cells, they do point towards an oxidative stress reaction. The protein panel analysis supports the hypothesis of oxidative stress related apoptosis. Additionally, based on the increased expression of the calcium and metabolic homeostasis related proteins it is plausible that the cells are exhibiting calcium-mediated mitochondrial apoptosis induced through oxidative stress. Past evidence has demonstrated oxidative stress, particularly reactive oxygen species, act upstream in this apoptotic pathway [21,22]. Increased expression of FOSB has been observed in cancer cells exposed to an accumulation of reactive oxygen species with pro-apoptotic outcomes [23]. Upregulation of EGFL7 has also been documented to have a cytoprotective effect in cells when faced with oxidative stress [24]; thus the increase seen here is potentially indicative of the cells responding to oxidative stress.

Based on previous literature, a possible explanation might be linked to catechol moieties in the insects. Catechol moieties cross-link chitin to protein in insect exoskeletons and are vital to cuticle sclerotization during development [25]. These catechol moieties can also act as precursors for certain quinonoids, particularly o-quinone, which are derived via the action of phenoloxidases, key components of insect immune systems and responses [25,26]. Quinones are cytotoxic through several mechanisms, one of which is the induction of oxidative stress through reduction to a semiquinone radical which reduces oxygen to superoxide radicals which then reform the quinone - a futile redox cycle which increases levels of hydrogen peroxide [27]. The suggested increase of HSP32 protein levels in the present study could be an indicator of increased hydrogen peroxide levels in the cells. Quinones are documented within insect cellular immune responses, in addition to hydrogen peroxide already being present as a defence mechanism produced by insect phagocytes [28]. Further, research has demonstrated that some quinones, depending on molecular structure, decompose above $100^{\circ} \mathrm{C}$ which may account for the more varied response seen in Figure 6, when cells were treated with insects heated above $100^{\circ} \mathrm{C}$ [29].

Although there is an increasing number of studies on insects and insect-derived molecules in cancer cell and mice models, very little is known about the effects of insects and their defence proteins on healthy human cells or healthy mice. A literature search on insects and primary human cells did not reveal any 
such studies. Since there is a thin line between cancerous and non-cancerous cells, we need to also be investigating how the cytotoxic effects observed in cancer cells relate to healthy cells.

\section{Declarations}

\section{Acknowledgements}

This work was supported by the UK Biotechnology and Biological Sciences Research Council Nottingham-Rothamsted Doctoral Training Partnership [grant number BB/J014508/1] and by the Swedish Research council FORMAS (grant \# 2014-417).

\section{Author Contributions}

DD and NS designed the research; DD conducted the majority of the research; DD and NS analysed data; DD wrote the draft paper; DD and NS edited and finalised the paper.

\section{Additional information}

The authors declare no competing interests.

\section{References}

1. Gulati, J.K. Child Malnutrition: Trends and Issues. Anthropologist 2010, 12, 131-140.

2. Nguyen, P.H.; Nguyen, H.; Gonzalez-Casanova, I.; Copeland, E.; Strizich, G.; Lowe, A.; Pham, H.; Truong, T. V.; Nguyen, S.; Martorell, R.; et al. Micronutrient intakes among women of reproductive age in Vietnam. PLoS One 2014, 9.

3. Magalhaes, R.J.S.; Clements, A.C.A. Mapping the risk of anaemia in preschool-age children: The contribution of malnutrition, malaria, and helminth infections in West Africa. PLoS Med. 2011, 8.

4. UNSCN 6th report on the world nutrition situtation - Progress in Nutrition; 2010;

5. Hamdy, a M.; Abdel Aleem, M.M.; El-Shazly, a a Maternal Vitamin A Deficiency during Pregnancy and Its Relation with Maternal and Neonatal Hemoglobin Concentrations among Poor Egyptian Families. ISRN Pediatr. 2013, 2013, 652148.

6. Seshadri, S. Prevalence of micronutrient deficiency particularly of iron, zinc and folic acid in pregnant women in South East Asia. Br. J. Nutr. 2001, 85, S87.

7. Bauserman, M.; Lokangaka, A.; Kodondi, K.K.; Gado, J.; Viera, A.J.; Bentley, M.E.; Engmann, C.; Tshefu, A.; Bose, C. Caterpillar cereal as a potential complementary feeding product for infants and young children: Nutritional content and acceptability. Matern. Child Nutr. 2015, 11, 214-220.

8. Kinyuru, J.N.; Kenji, G.M.; Njoroge, M.S. Process development, nutrition and sensory qualities of wheat buns enriched with edible termites (Macrotermes subhylanus) from Lake Victoria region, Kenya. African J. Food, Agric. Nutr. Dev. 2009, 9, 1739-1750. 
9. Rumpold, B.A.; Schlüter, O.K. Nutritional composition and safety aspects of edible insects. Mol. Nutr. Food Res. 2013, 57, 802-823.

10. Christensen, D.L.; Orech, F.O.; Mungai, M.N.; Larsen, T.; Friis, H.; Aagaard-Hansen, J. Entomophagy among the Luo of Kenya: a potential mineral source? Int. J. Food Sci. Nutr. 2006, 57, 198-203.

11. Pettit, G.R.; Meng, Y.; Herald, D.L.; Knight, J.C.; Day, J.F. Antineoplastic agents. 553. The Texas grasshopper Brachystola magna. J. Nat. Prod. 2005, 68, 1256-1258.

12. Suo, H.; Sun, P.; Wang, C.; Peng, D.; Zhao, X. Apoptotic effects of insect tea in HepG2 human hepatoma cells. CYTA - J. Food 2016, 14, 169-175.

13. Wu, R.A.; Ding, Q.; Lu, H.; Tan, H.; Sun, N.; Wang, K.; He, R.; Luo, L.; Ma, H.; Li, Z. Caspase 3-mediated cytotoxicity of mealworm larvae (Tenebrio molitor) oil extract against human hepatocellular carcinoma and colorectal adenocarcinoma. J. Ethnopharmacol. 2020, 250, 112438.

14. Chernysh, S.; Kim, S.I.; Bekker, G.; Pleskach, V.A.; Filatova, N.A.; Anikin, V.B.; Platonov, V.G.; Bulet, P. Antiviral and antitumor peptides from insects. Proc. Natl. Acad. Sci. U. S. A. 2002, 99, 12628-12632.

15. The Uniprot Consortium UniProt: a worldwide hub of protein knowledge. 2019, 47, 506-515.

16. Chelikani, P.; Fita, I.; Loewen, P.C. Diversity of structures and properties among catalases. Cell. Mol. Life Sci. 2004, 61, 192-208.

17. Goodsell, D.S. Catalase. RCSB Protein Data Bank 2004.

18. Guo, Y.; Zhang, T.; Jiang, B.; Miao, M.; Mu, W. The effects of an antioxidative pentapeptide derived from chickpea protein hydrolysates on oxidative stress in Caco-2 and HT-29 cell lines. J. Funct. Foods 2014, 7, 719-726.

19. Katayama, S.; Fan, M.Z.; Ishikawa, S.; Mine, Y. Phosphopeptides derived from egg yolk phosvitin upregulate gamma-glutamylcysteine synthetase and antioxidant enzymes against oxidative stress in human intestinal epithelial cells. Abstr. Pap. Am. Chem. Soc. 2006, 232, 345.

20. Puerto, M.; Pichardo, S.; Jos, Á.; Prieto, A.I.; Sevilla, E.; Frías, J.E.; Cameán, A.M. Differential oxidative stress responses to pure Microcystin-LR and Microcystin-containing and non-containing cyanobacterial crude extracts on Caco-2 cells. Toxicon 2010, 55, 514-522.

21. Görlach, A.; Bertram, K.; Hudecova, S.; Krizanova, O. Calcium and ROS: A mutual interplay. Redox Biol. 2015, 6, 260-271.

22. Hempel, N.; Trebak, M. Crosstalk between calcium and reactive oxygen species signaling in cancer. Cell Calcium 2017, 63, 70-96.

23. Park, J.; Na, H.; Jin, H.; Kim, K. Increased Expression of FosB through Reactive Oxygen Species Accumulation Functions as Pro-Apoptotic Protein in Piperlongumine Treated MCF7 Breast Cancer Cells. Mol. Cells 2019, 42, 884-892.

24. Xu, D.; Perez, R.E.; Ekekezie, I.I; Navarro, A.; Truog, W.E.; Physiol, A.J.; Cell, L.; Physiol, M. Epidermal growth factor-like domain 7 protects endothelial cells from hyperoxia-induced cell death. Am. J. Physiol. Cell. Mol. Physiol. 2008, 294, 17-23. 
25. Kramer, K.J.; Kanost, M.R.; Hopkins, T.L.; Jiang, H.; Zhu, C.; Xu, R.; Kerwin, J.L.; Turecek, F. Oxidative conjugation of catechols with proteins in insect skeletal systems. Tetrahedron 2001, 57, 385-392.

26. González-santoyo, I.; Córdoba-aguilar, A. Phenoloxidase: a key component of the insect immune system. Entomol. Exp. Appl. 2012, 142, 1-16.

27. O'Brien, P.J. Molecular mechanisms of quinone cytotoxicity. Chem. Biol. Interact. 1991, 80, 1-41.

28. Nappi, A.J.; Vass, E. Melanogenesis and the Generation of Cytotoxic Molecules During Insect Cellular Immune Reactions. Pigment Cell Res. 1993, 6, 117-126.

29. Sousa, E.T.; Da Silva, M.M.; De Andrade, S.J.; Cardoso, M.P.; Silva, L.A.; De Andrade, J.B. Evaluation of thermal stability of quinones by thermal analysis techniques. Thermochim. Acta 2012, 529, 1-5.

30. Sambuy, Y.; De Angelis, I.; Ranaldi, G.; Scarino, M.L.; Stammati, A.; Zucco, F. The Caco-2 cell line as a model of the intestinal barrier: Influence of cell and culture-related factors on Caco-2 cell functional characteristics. Cell Biol. Toxicol. 2005, 21, 1-26.

31. Hidalgo, I.J.; Raub, T.J.; Borchart, R.T. Characterization of the human colon carcinoma cell line (Caco2) as a model system for intestinal epithelial permeability. Gastroenterology 1989, 96, 736-739.

32. Glahn, R.P.; Lee, O.A.; Yeung, A.; Goldman, M.I.; Miller, D.D. Caco-2 cell ferritin formation predicts nonradiolabeled food iron availability in an in vitro digestion/Caco-2 cell culture model. J. Nutr. 1998, 128, 1555-61.

33. Garrett, D.A.; Failla, M.L.; Sarama, R.J. Estimation of carotenoid bioavailability from fresh stir-fried vegetables using an in vitro digestion / Caco-2 cell culture model. J. Nutr. Biochem. 2000, 11, 574580 .

\section{Figures}




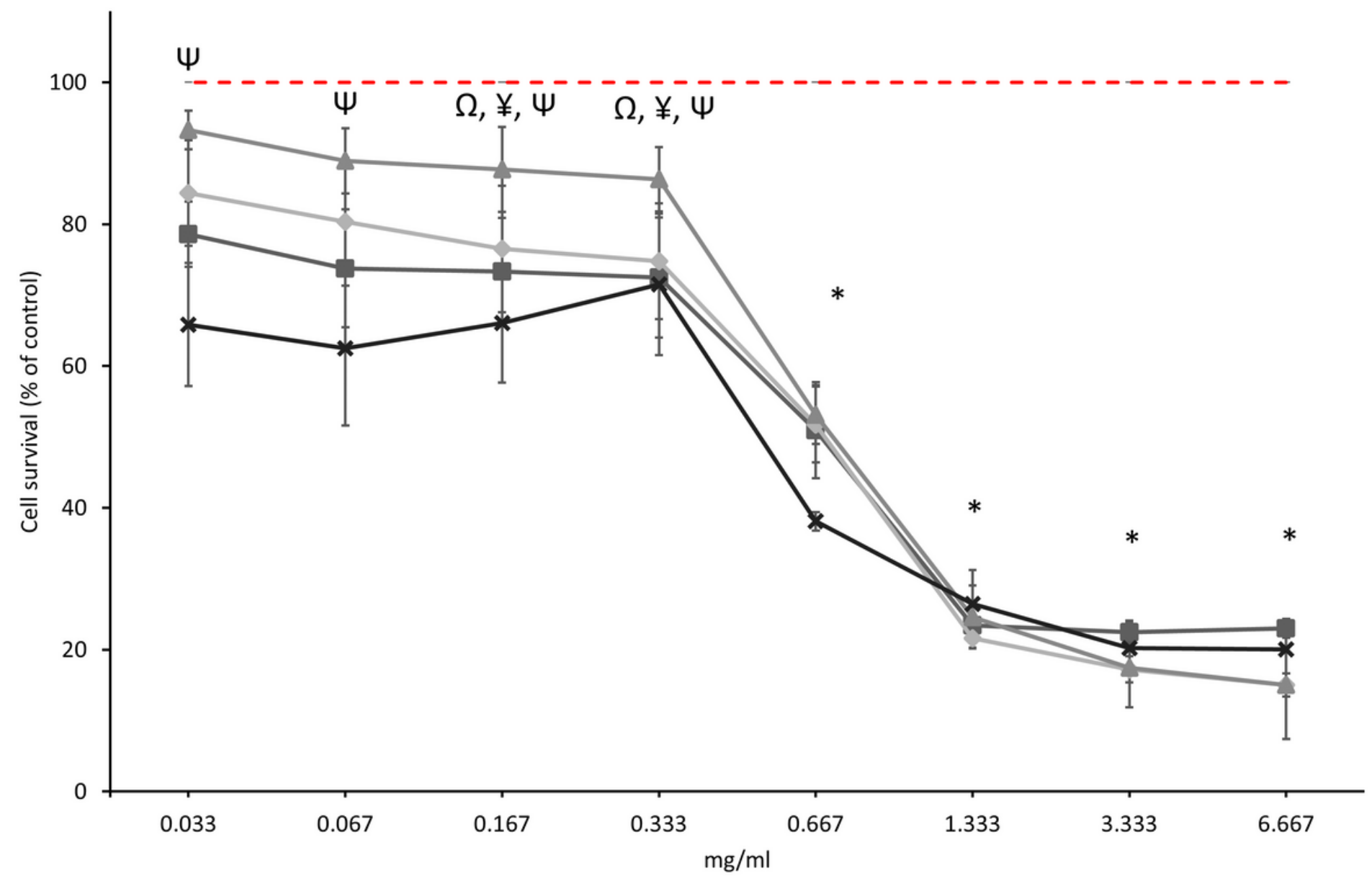

G. bimaculatus $\leadsto-$ S. gregaria $\_$T. molitor $*$ A. domesticus

Figure 1

Cell survival, estimated by total protein from live cells, expressed as a percent of untreated controls. The cells were treated with varying dilutions of insect digests (data are means $\pm S E, n=4$ ). The undiluted digest contained $66.67 \mathrm{mg}$ insect flour $/ \mathrm{ml}$ of digest. $\Omega$ indicates significant difference of $\mathrm{G}$. bimaculatus from control, $¥$ indicates significant difference of $S$. gregaria from control, $\Psi$ indicates significant difference of A. domesticus from control, * indicates significant difference from control for all insects $(p<0.05)$. 


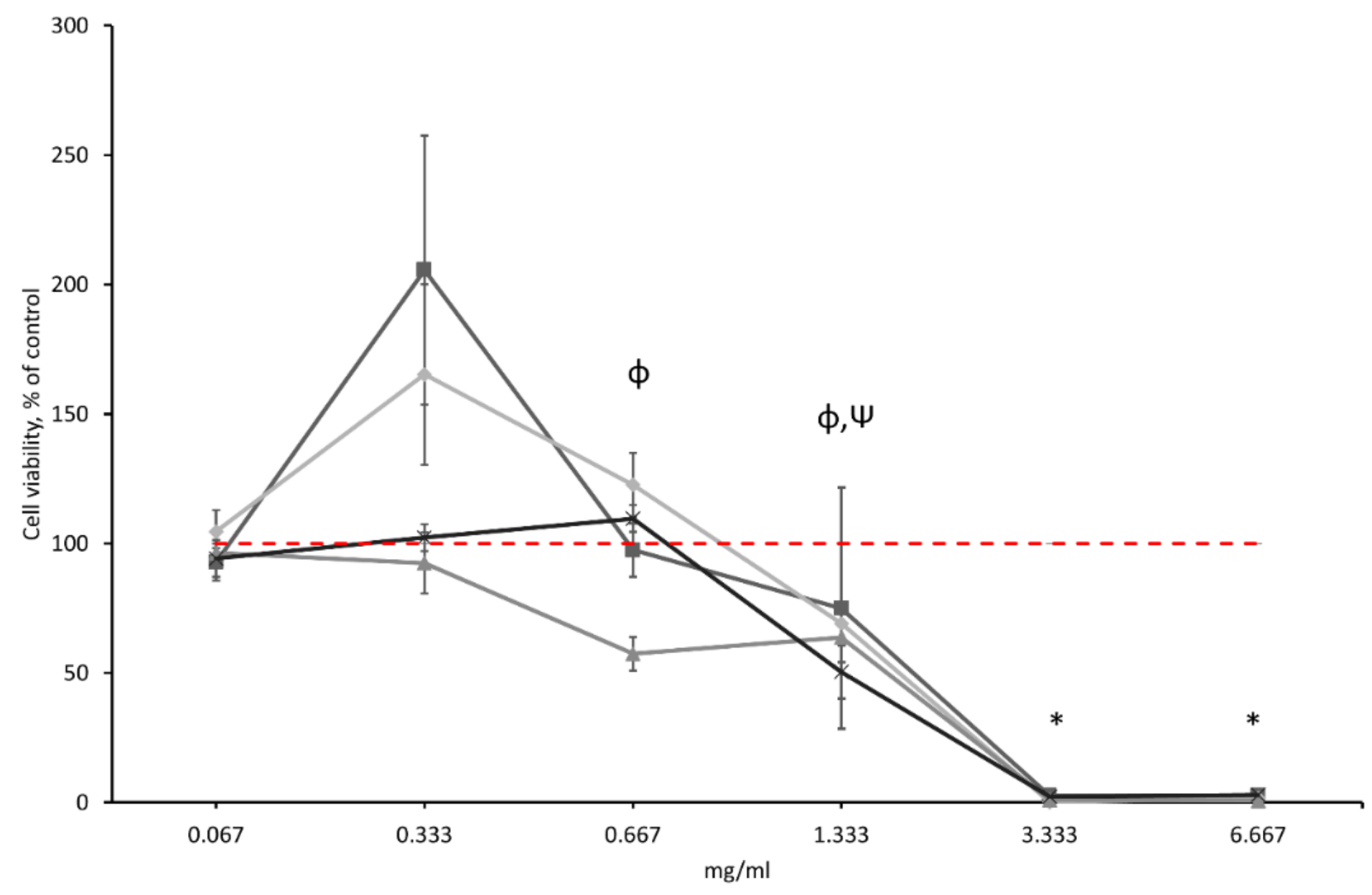

$\dashv$ - bimaculatus $\multimap$ S. gregaria $\leftarrow$. molitor $*$ A. domesticus

\section{Figure 2}

Cell viability (estimated by the MTT assay) as percentage of control (means $\pm S E, n=3$ ) of cells treated with varying dilutions of insect digests. $\varphi$ indicates significant difference of T. molitor from control, $\Psi$ indicates significant difference of $A$. domesticus from control, * indicates significant difference from control for all insects $(p<0.05)$. 


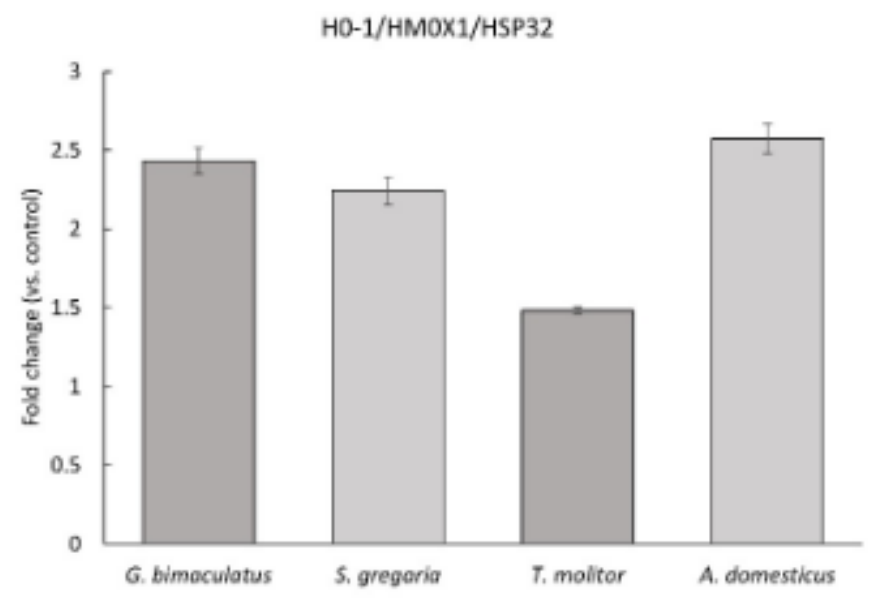

(a)
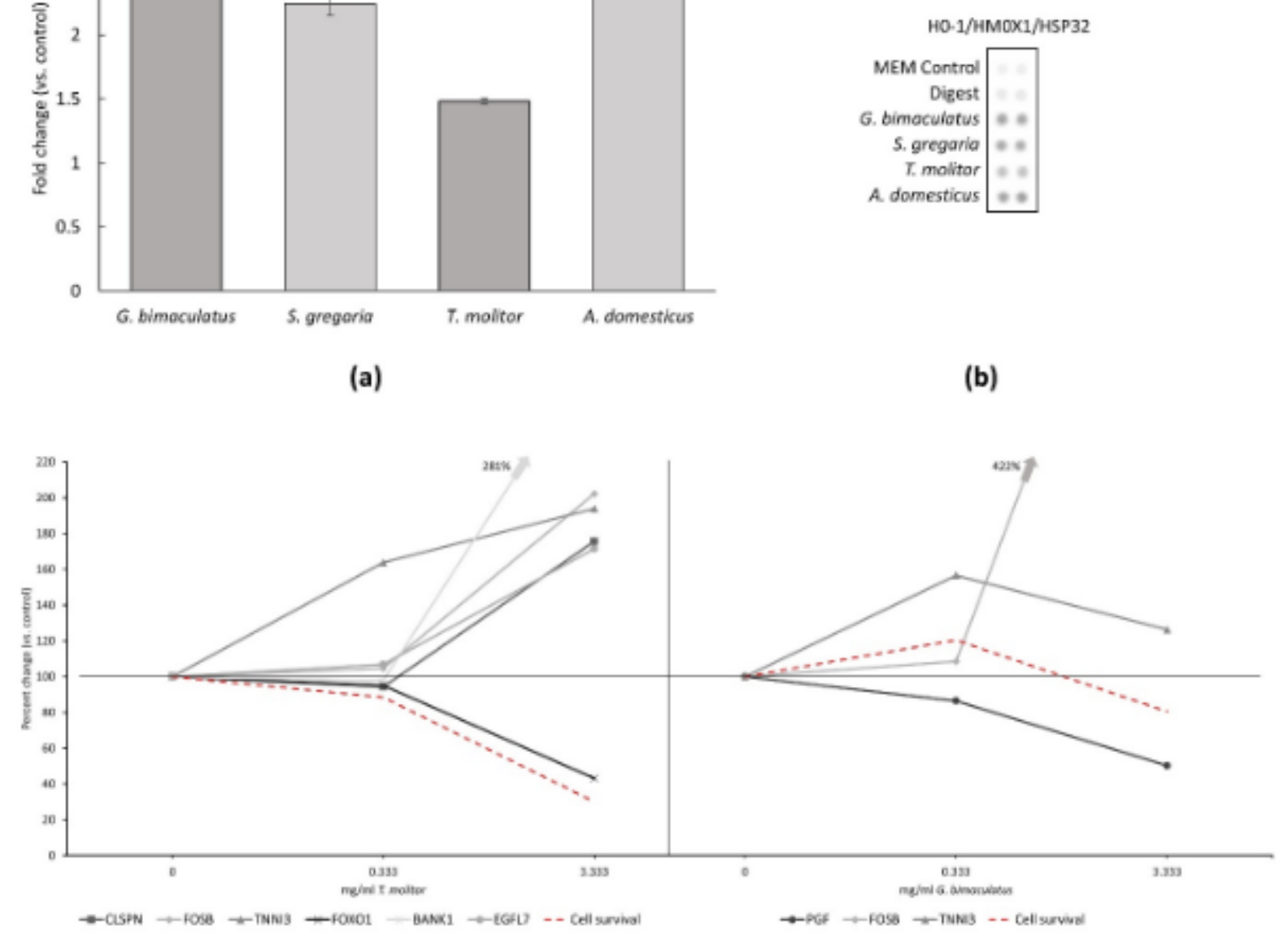

(c)

(d)

\section{Figure 3}

Stress-related protein expression of Caco-2 cells exposed to insect digests at varying concentrations. (a) Proteome Profiler \pm apoptosis arrays on Caco-2 cells exposed to insect digests at $3.333 \mathrm{mg} / \mathrm{ml}$ for 24 hours. Fold changes $>1$ (100\% increase/decrease) were considered significant. H01/HM01/HSP32 fold changes represent an increase (b) Representative blot from Proteome Profiler \pm analysis showing protein array data for H0-1/HMOX/HSP32. (c) Data from OLink Proteomics analysis on confluent/differentiated Caco-2 cells exposed to insect digests at two concentrations for 2 hours $(n=3)$. Fold changes $>0.5(50 \%$ increase/decrease) were considered significant. Proteins with significant changes across increasing exposure to T. molitor (d) Stress-related proteins (OLink proteomics) with significant changes across increasing exposure to $\mathrm{G}$. bimaculatus. 


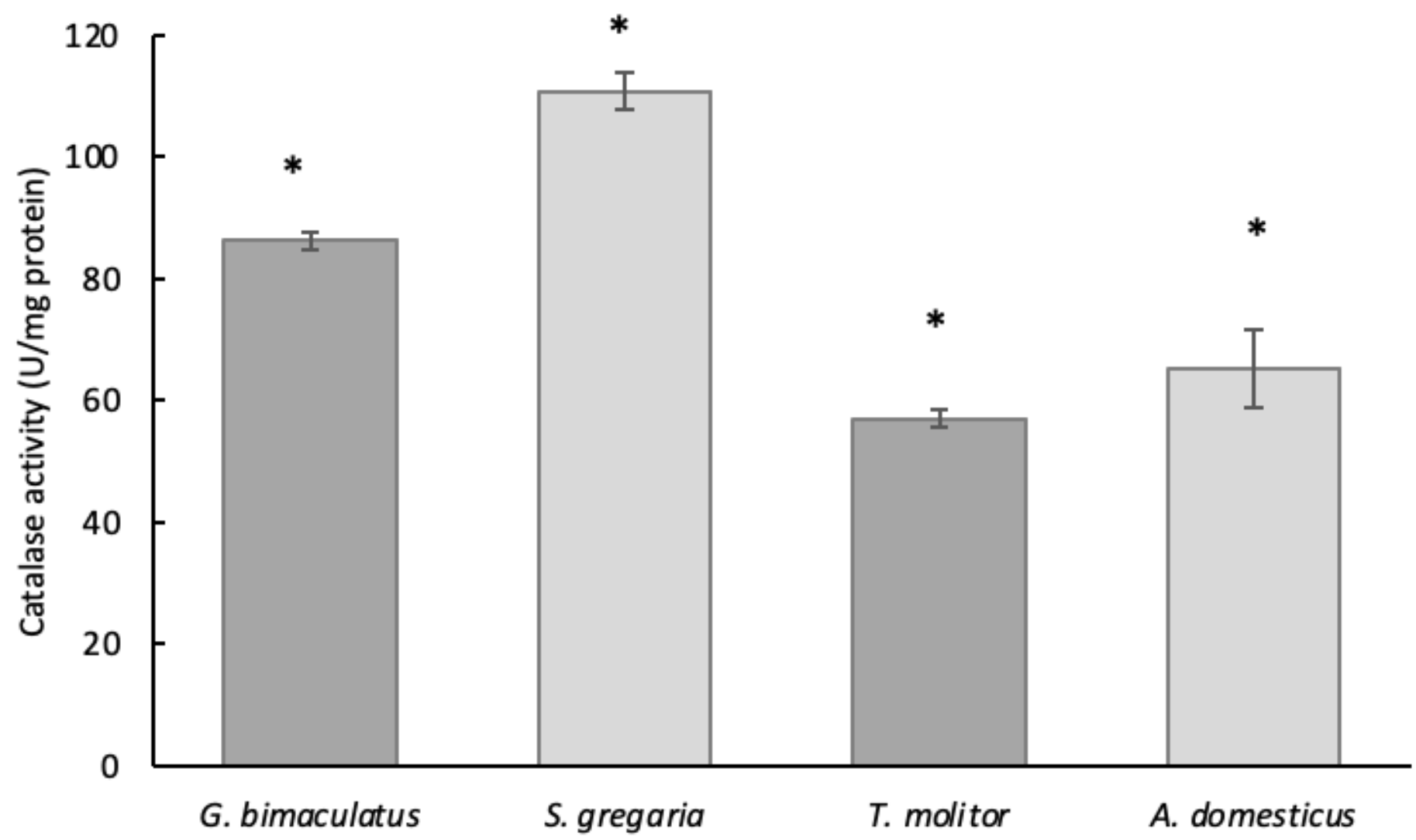

Figure 4

Catalase activity $(\mathrm{U} / \mathrm{ml})$ normalised to total protein $(\mathrm{mg} / \mathrm{ml})$ in human intestinal Caco-2 cells treated for 24 hours with insect digests at dilution $3.335 \mathrm{mg} / \mathrm{ml}$ (means $\pm S E, n=2$ ). An asterisk (*) indicates a significant difference $(p<0.05)$ from the digest control. There was no significant difference between untreated cells and cells treated with blank digestion fluids $(p=0.85)$. 


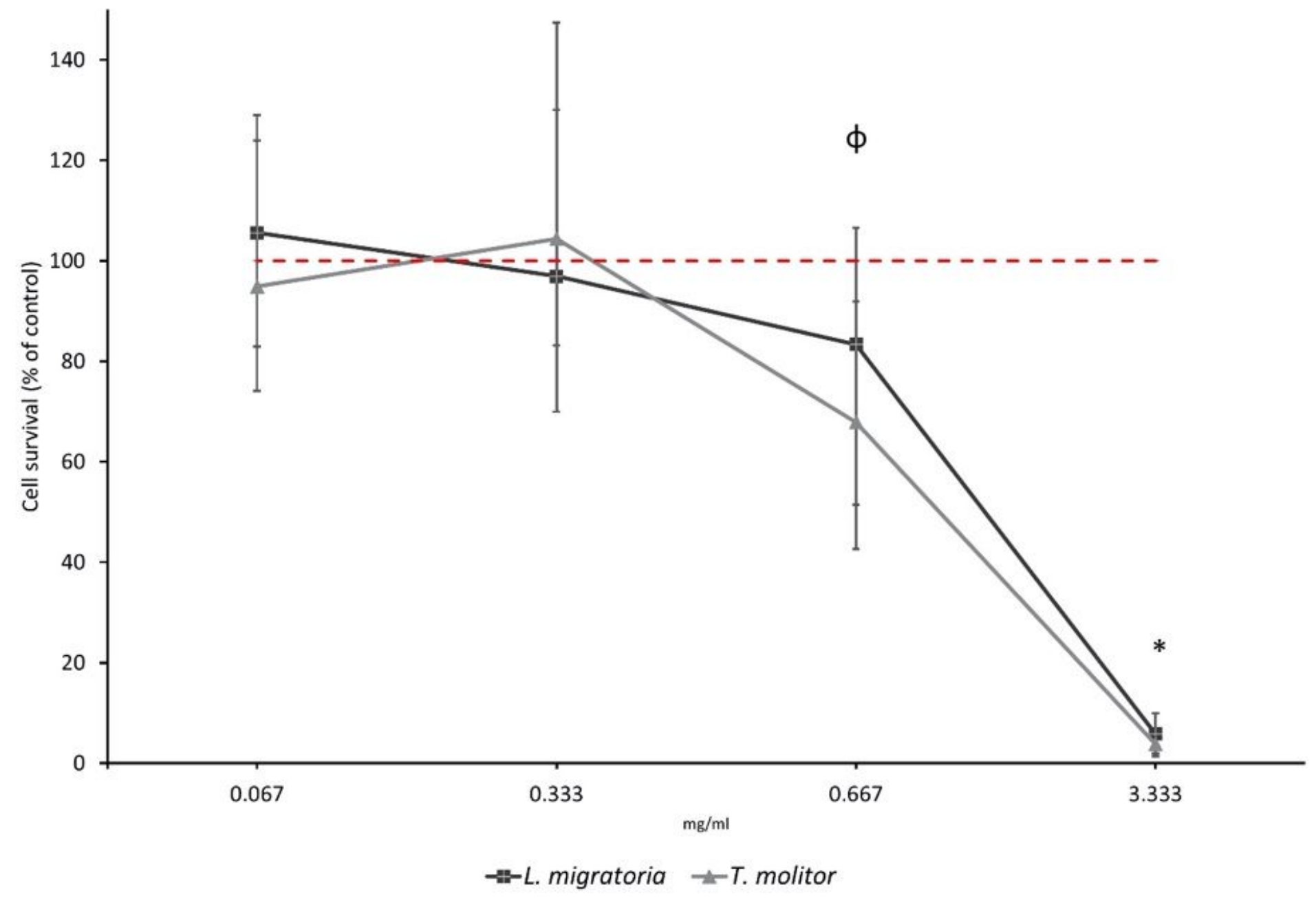

Figure 5

Cell survival, estimated by total protein from live cells, expressed as a percent of the untreated control of insects from the Netherlands. The cells were treated with varying dilutions of insect digests (data are means $\pm \mathrm{max} / \mathrm{min}, \mathrm{n}=2$ ). T-tests done using technical cell well replicates, $\mathrm{n}=6 . \varphi$ indicates significant difference of T. molitor from control, * indicates significant difference from control for all insects $(p<$ 0.05). 


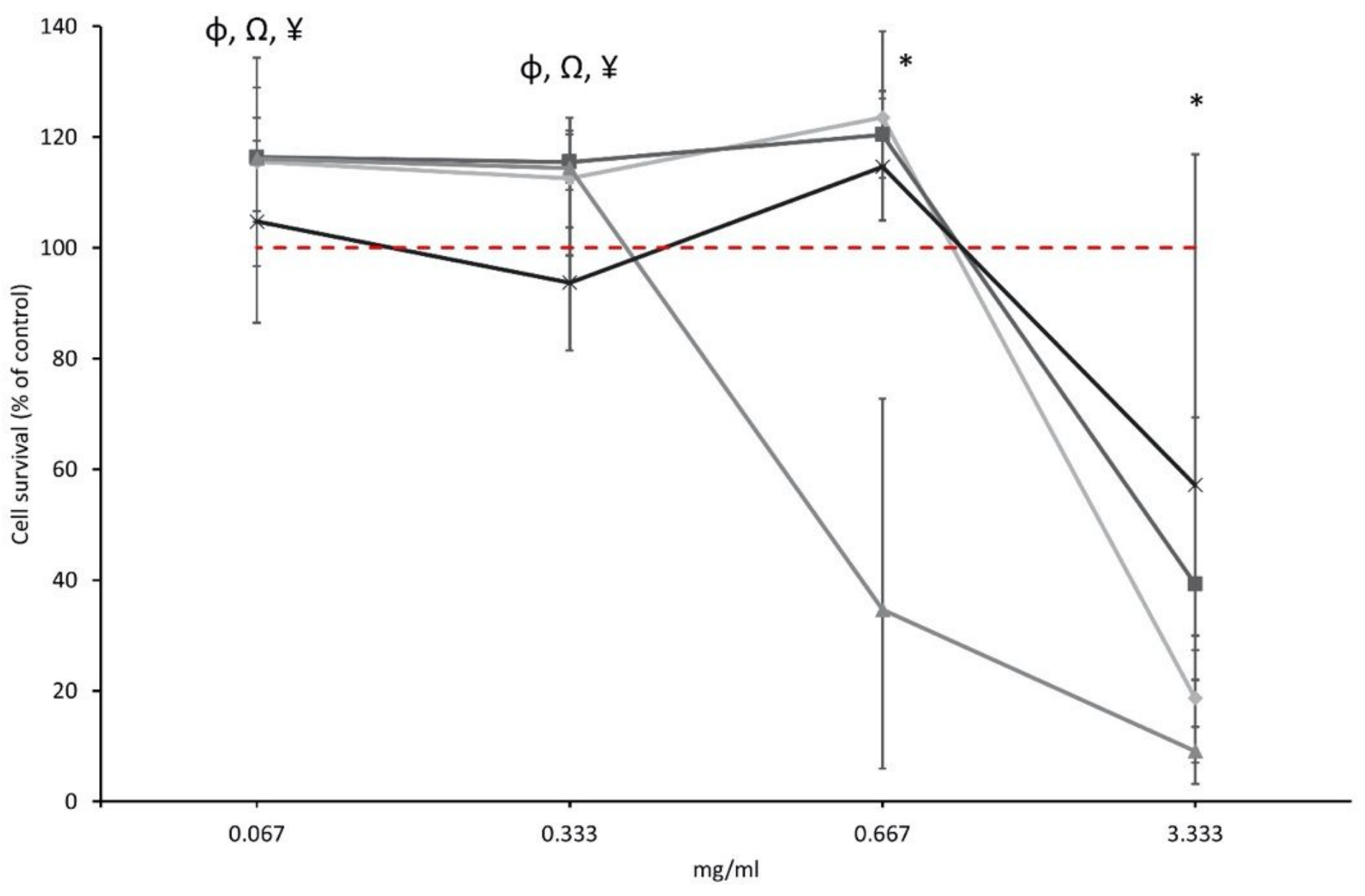

$\rightarrow$ G. bimaculatus $\rightarrow-S$. gregaria $\rightarrow$. molitor $*$ A. domesticus

\section{Figure 6}

Cell survival, estimated by total protein from live cells, expressed as a percent of the untreated control of insects heated to $105^{\circ} \mathrm{C}$ for 60 minutes. The cells were treated with varying dilutions of insect digests (data are means $\pm \max / \min , n=2$ ). T-tests done using technical cell well replicates, $n=6$. $\varphi$ indicates significant difference of T. molitor from control, $\Omega$ indicates significant difference of $G$. bimaculatus from control, $¥$ indicates significant difference of $\mathrm{S}$. gregaria from control, * indicates significant difference from control for all insects $(p<0.05)$.

\section{Supplementary Files}

This is a list of supplementary files associated with this preprint. Click to download.

- FigureS1.jpeg 